Journal of Social Sciences 3 (1): 27-35, 2007

ISSN 1549-3652

(C) 2007 Science Publications

\title{
Effective Meeting in Graduate Research Student Supervision
}

\author{
${ }^{1}$ Norhasni Zainal Abiddin, ${ }^{2}$ Mel West \\ ${ }^{1}$ Department of Professional Development and Continuing Education, Faculty of Educational Studies \\ Universiti Putra Malaysia, 43400 Serdang, Selangor, Malaysia \\ ${ }^{2}$ School of Education, Humanities Building, The University of Manchester, Oxford Road, Manchester \\ M13 9PL, United Kingdom
}

\begin{abstract}
Meeting with supervisor is part of the practices for any graduate research students. However, was the meeting effectively conducted? Did the meeting really helped the student to progress in their research and did the supervisor given proper guidance and advices to the student during the meeting? This article focuses on the practices on supervision especially the effective methods of conducting meeting from twelve Ph.D students studied at Manchester, United Kingdom of three major disciplines of study namely Arts, Science and Social Sciences. It reviewed the major findings of the research through in-depth interviews. The results had shown that in order to progress well in their research, they must no doubt be involved in more regular meetings or discussions process and to go through certain levels before, during and after each meeting. Those levels are very important to be implemented in order to ensure that the meetings with the supervisor have great implication to the research students. Lecturers, students and especially the foreign students should practice it in order to optimise the effectiveness of the meeting and relationship between student and supervisor.
\end{abstract}

Key words: Foreign student, graduate, meeting, model, supervision, supervisor

\section{INTRODUCTION}

Supervision is widely recognised as being complex and multidimensional. Ballard and Clanchy ${ }^{[1]}$ describe research student supervision as a blend of academic expertise and the skilful management of personal and professional relations. On the other hand, the Council of Graduate Schools ${ }^{[2]}$ suggests that there are two major aspects to the supervision of graduate research students:

The first and more important has to do with creativity and involves the ability to select problems, to stimulate and enthuse students and to provide a steady stream of ideas. The second aspect is concerned with the mechanics of ensuring that the student makes good progress.

Some writers, such as Binns and Potter ${ }^{[3]}$ Hockey $^{[4]}$ and Smith $^{[5]}$ discuss the patterns and process of supervision and especially the roles of postgraduate students in producing effective supervision. In view of this research, effective supervision of research students is acknowledged to be a crucial factor in the latter's successful completion of the $\mathrm{Ph} . \mathrm{D}^{[6]}$. How well they are supervised is likely to be linked to the way they choose to occupy their role. This kind of experience is very interesting and meaningful to appropriate persons like students, supervisors and schools in order that they may examine what they should do and how they should go about playing their roles optimally.

A literature search has provided evidence that the student/supervisor relationship is vital to the Ph.D process. The literature includes statements about the single most important problem, in the eyes of many respondents, being the quality of supervision ${ }^{[7]}$. Various books have approached the acquisition of $\mathrm{PhDs}$, including the management of the supervisor/student relationship $^{[8]}$ and many departments carry out their own surveys in an attempt to assess their performance in the supervision of their students ${ }^{[13]}$.

Bond $^{[30]}$ suggests that effective research supervision is essential as, without it, students may undertake poorly planned work, or work on too large a scale which cannot be completed in the time available. Clarke $^{[31]}$ and Sheehan ${ }^{[32]}$ also indicate that the supervisor is the principal source of instruction, support and guidance for the student. Therefore, it has been shown that a good supervisor, who gives timely and appropriate guidance and advice can lead to the success

Corresponding Author: Norhasni Zainal Abiddin, Department of Professional Development and Continuing Education, Faculty of Educational Studies, Universiti Putra Malaysia, 43400 Serdang, Selangor, Malaysia. 
of the research as well as that of the researcher ${ }^{[34-37]}$. Such guidance and advice should be given to research students most effectively involved in a meeting. Therefore, the patterns and practices or the meeting process is important to research student in order to gain more benefits and to ensure research progress.

It was known that the student and supervisor were aware of their respective responsibilities. They were also aware the importance of developing good relationship between them in order to ensure that the students' research went smoothly. However, the study made by researcher earlier had found that those Ph.D students did not gain maximum benefit during the meeting with their supervisor. It was always happened that when they came out from the meeting with supervisor, there were still more unresolved problems or questions. Therefore, how could the students be able to move on to the next step when there were still unresolved problems with their research? Hence, the meeting was considered unsuccessful and not effective since it was not able to resolve the meeting agenda. At the same time, the students will be questioning the effectiveness of the meeting with their supervisor and how could they maximize the benefit of the meeting. This study will therefore, answering the above question. The implication from this research will be the students would be more concern about time management and the steps that need to be taken before, during and after their meeting with the supervisor. Their research would be progressing better and efficiently if they had managed to organize and conduct effective meetings with their supervisor and subsequently resolved any problems that occurred during conducting their research.

Research student supervision: Essentially, learning involves two parties, the teacher (also known as the supervisor, mentor, coach) and the student (known as the trainee, mentee, mentoree, coachee, protégé). The relationship between the teacher and student plays an important role in promoting the student's objectives. Many authors have mentioned the importance of the relationship between a student and a supervisor in this context $^{[8,16,38-41]}$, particularly where the two work closely over a number of years. However, sometimes a problem of compatibility occurs between them and therefore, Hockey ${ }^{[14]}$ and Wilkin ${ }^{[37]}$ suggest that they both need to know their roles in order to ensure a good relationship.

Numerous researchers have pointed out that there is a high proportion of Ph.D students who fail to complete their studies in the UK. The most frequently cited reasons are problems with supervision ${ }^{[5,7,22,28,42-}$ 42,45-47]. According to Russell ${ }^{[48]}$, the examination of supervision has the potential to make an important contribution to the quality of postgraduate research. Therefore, supervision is concerned with the mechanics of ensuring that the student makes good progress towards completion ${ }^{[4]}$. On the other hand, the supervision literature indicates that ethical, technical and methodological problems can be minimised or prevented if all the participants in the relationship strive to enter it with clear expectations for their respective roles and about the rules for their interactions ${ }^{[49-51]}$. Therefore, both on a departmental and individual basis, the supervisor must be diligent about explicitly working with students to establish mutual expectations, responsibilities and benefits for working together and with other interested parties ${ }^{[8]}$.

Supervision practices: The Council of Graduate Schools ${ }^{[2]}$ proposes several aspects which should be considered when developing best practices in the supervision of graduate students. They have to do with creativity and involve supervision as a central process. Hockey ${ }^{[4]}$ points out that this process should be open to negotiation and Bargar and Mayo-Chamberlain ${ }^{[24]}$ propose that it should be open to change. Connell ${ }^{[52]}$ argues that it is incumbent upon the supervisor to bridge gaps in communication during the various stages of research by requesting regular meetings or updates. His study finds that as research progresses, students move from looking to supervisors for direction and guidance towards forming a critical friendship. Moses ${ }^{[9]}$ argues that at each stage of the research progress, students are likely to need different forms of guidance. They need particular guidance on when to stop data collection and analysis, when to start drafting the thesis and how to structure $\mathrm{it}^{[9]}$. Thus, the supervisors are expected and assumed to be guides ${ }^{[21,26,32,39,48,50,53]}$ and critical friends ${ }^{[4,54]}$. On the other hand, they should also be able to adopt flexible supervision strategies depending on the individual requirements, which are influenced by the attributes of the particular student ${ }^{[4,15,50,59]}$. This is due to the fact that Ph.D students are not homogenous, but highly diverse in terms of academic ability, personality attributes, motivation and attitude. Hence, how supervisors respond to students will, in part, be conditioned by these different factors and applying the same rigid strategy for each student may not always work effectively ${ }^{[15]}$. Burgess et al. ${ }^{[55]}$ also pick up the theme of changing research stages and the need for a supervisor to be flexible in an attempt to meet the needs of individual students. Supervisors who have this flexibility can be more helpful to their research students $^{[13]}$. Hockey ${ }^{[4]}$ agrees with this statement and 
suggests that supervisors initiate a tight structure of control solely with the students whom they consider to be weak. However, research has found that strong and highly motivated students also demand such a structure. Conversely, with this kind of student, supervisors might need considerable latitude in order to express themselves intellectually. In this case, a relatively unstructured strategy might develop with supervisors being primarily reactive to students' demands.

Phillips and $\mathrm{Pugh}^{[8]}$ point out that the acquisition of skills by postgraduate students should be effected as professional learning conducted under their own management. In other words, research students have to take responsibility for managing their own learning and getting a Ph.D. They are also responsible for determining what is required as well as for carrying it out and must always keep in touch in regular meetings with the supervisor ${ }^{[9-11]}$. Moses ${ }^{[12]}$ argues that supervisors expect students to be diligent, hardworking, energetic, keen, tenacious and conscientious and to have a sense of urgency. They also expect students to be enthusiastic and motivated towards research work, to be pleasant at work and to contribute to a good working environment. Also, students should give continual feedback, so that the supervisor can give informed instruction.

The responsibility for completing a Ph.D within a reasonable length of time clearly lies with both the student and the supervisor ${ }^{[13-18]}$. Both of them should play their role effectively and maintain a good relationship during the period of the programme $e^{[10,19-23]}$. The relationship can be seen as a personal and professional relationship between the two ${ }^{[1,4,18,24-25]}$. This relationship is dependent upon the characteristics of the persons involved, disciplinary differences in the ways knowledge is advanced and the different learning tasks facing students due to the demands of their field. The relationship between the student and supervisor involves selecting a research topic, planning the research, identifying and acquiring the necessary resources, managing the project, actively conducting the research, carrying out the literature review, analysis and interpretation of the data, writing the thesis, defending it and possibly publication ${ }^{[25]}$. Students should expect to work within deadlines ${ }^{[8,17-18,26]}$ and to have a planned timetable ${ }^{[6,27-28]}$. Consequently, the supervisory process requires constant adjustment, great sensitivity and interpersonal skill on the part of both the supervisor and student ${ }^{[4,25,29]}$.

Building effective communication in supervision: In preparing for Ph.D research, students need a lot of communication with their supervisors. Therefore, a supervisor and student must have a very good relationship and be very close to each other. Good communication between students and their supervisor is the most important elements of supervision ${ }^{[4,8,13,15,24,50,53,56,58]}$. Without open and honest communication it is very difficult to identify the nature of and reasons for the shortfalls perceived by the student. Both parties should be open to criticism, willing to listen to each other and to talk openly ${ }^{[13]}$ and trustworthy ${ }^{[4,26,57]}$. According to Donald et al. ${ }^{[58]}$, personality factors might involve personality clashes, barriers to communication due to age, cultural, or language differences, or personal differences in the approach to work. Therefore, students bear their own degree of responsibility in dealing with these clashes.

Haksever and Manisali ${ }^{[13]}$ and Hockey ${ }^{[4]}$ mention that, as Ph.D. programmes in the British education system are not based on formal lectures and credits, the supervision requirements of Ph.D students in the UK are generally greater than those who study under more formal and structured programmes, as is the case in the US and Europe. Therefore, the role of the Ph.D supervisor in the British education system is critical to a successful Ph.D process. Poor supervision can have a significant impact on students, not only limiting the quality of their work, but also their motivation. At the end of the programme, the students are required to submit their theses. This underlines that the studentsupervisor relationship is very important in ensuring that the student makes consistent progress and successfully manages to present his/her thesis on time and to standard ${ }^{[8,16,33,39-41]}$. It is, therefore, to an extent the students who have to 'manage' the effectiveness of their supervisor because it will help their progress if they are guided well while conducting the research and preparing the thesis. It is, however, recognised that many educational institutions are inadequately prepared in terms of structures, policies, procedures and support to enable effective research supervision to take place ${ }^{[22]}$.

In a meeting, two or more people come together for the purpose of discussing a (usually) predetermined topic, often in a formalised setting. In addition to coming together physically (in real life, face to face), communication lines and equipment can also be set up to have a discussion between people at different locations, e.g. a conference call or an e-meeting. Meetings are an important vehicle for human communication. They are so common and pervasive in organizations, however, many took them for granted and forget, unless properly planned and executed, meeting could be a terrible waste of precious resources. They are similar in graduate research student 
supervision. Student and supervisor have certain objectives to fulfill, therefore effective meeting could make student's work quicker and he or she can move to another stage of doing research effectively.

In general, meetings fall into three categories: (1) status meetings, generally leader-led, which is about reporting through one-way communication; (2) work meetings, which produce a product or intangible result such as decision; and (3) meetings which never should have happened. In graduate research student supervision, work meeting is appropriate as student reports his/her research progress to his/her supervisor. The advice and guidance given could bring students to move forward and solve their research problems.

During the meeting with supervisor, the student normally suggests having a graduate student log. This log involves the student writing up what is transacted in the supervision meeting. It should end with a response to 'where to from here?' The $\log$ is an invaluable resource in the early stages of a graduate research thesis project when a great deal of structure is needed to get the process going and the topic focused. The graduate supervision $\log$ is an example of using new contractualist technologies of management to make the supervision relationship rationally accountable in ways which are likely to facilitate successful graduate student completion of the task. This will need the explicit skilling of graduate students in all the competencies and knowledge that go into the successful production of a Ph.D thesis ${ }^{[18]}$.

Many students are unsure as to what to expect from supervision meetings. Much depends on the stage of the research and the discipline. However, after the stage of 'getting to know you' the following agenda will generally be followed: administration matters, review of progress, goal setting, discussion and exchange of ideas. Generally a meeting will be somewhere between 30 minutes and two hours. Once again, student will generally have a meeting every one or two weeks. This is likely to change over time (as will the relationship). Student will probably meet his/her supervisor(s) frequently when first putting together their proposal and again towards the end when they are writing up. Midway, when he/she is likely to be doing fieldwork or research the need to see the supervisor(s) will be much lesser. However, during this time it is probably a good idea to send a few quick emails quite regularly to update the progress. This is an issue that should be decided with the supervisor(s). Some supervisors and students prefer unstructured informal meetings, whereas others like to stick to a pre-arranged format. Student should send the supervisor some sort of agenda well before the meeting, including any drafts or readings that student would like to be discussed. Also, it is good to take notes during the meeting and send these 'minutes' to the supervisor(s) after the meeting as a follow up and verification of any decisions made during the meeting $^{[18]}$.

\section{MATERIALS AND METHODS}

Twelve Ph.D students from various fields of study and years were interviewed. There were all from three main universities in Manchester, namely University of Manchester, UMIST and University of Salford. Based on the distribution of subjects available in these universities, they were divided into three groups namely arts, science and social science. Those groups were built based on the nature of the field itself. In this connection it was seen that arts courses involve research into human, materials and language and science courses involve laboratory and studio based work, while social science courses are more investigation into human ecology.

These in-depth interviews were based on an interview schedule, consisting of open-ended questions. They were conducted based on a semi-structured interview schedule and using tape recorder to ensure accuracy. The objective was to obtain information in relation to the research questions. One of the data sources for qualitative research is direct speech of the people (informants) about their experiences, opinions, feelings and knowledge. Therefore, the interviews were managed to obtain the real views of the interviewees. The interview process was similar for all informants. All interviews were held at mutually agreed appointment times. The interviews were tape recorded and transcribed manually.

\section{RESULTS AND DISCUSSION}

Students must maintain a good relationship with their supervisor in order to enjoy their life as a Ph.D student. Newly started students must get in touch with their supervisor early, preferably before the official start of term and ensure that they fully understand the formal requirements of their degree. They should aim to get into a position to start well-focused work as soon as possible. Agreement should be reached between both parties pertaining to the meeting arrangements and frequency. As stated in research student policies, meetings should be held once a week during the first term and may then move on to be fortnightly when the work is well under way.

Students have to discuss with their supervisor the type of guidance and comment they find most helpful, agreeing a schedule of meetings, initiating supervisory 
sessions where necessary and setting the agenda for supervisory sessions. It is important that they can express their own interests and ideas to their supervisor as early as possible and they turn up to meetings well prepared, as they will be doing most of the talking. If, for some reason, students have nothing new to say, or they are in the middle of working something out, it may be preferable to postpone the meeting. It is also the responsibility of students to submit written work as and when required by their supervisor. Research work and progress may be discussed with the supervisor in many other ways as appropriate, like in meetings, by e-mail and on the telephone. Students are advised to rewrite sections before they go to the supervisor. The more students write and discuss the content and style of writing with their supervisor in the early years, the more straightforward will be the production of the first draft. If the supervisor does not request written work, then it is still the responsibility of the student to submit it because some supervisors give students freedom to plan their own research work as long as they can maintain progress in accordance with the plan agreed with them. In particular, written material should be submitted as required to the supervisor in sufficient time to allow for comments and discussion before proceeding to the next stage.

Model of effective meeting in supervision: Most students prefer to meet their supervisor frequently, especially in their first year. When they have moved to the second year, they reduce the meetings to once every two or three weeks. On the other hand, they tend to meet once a month or less in their third year. This means that the further they progress, the fewer meetings they have with their supervisors. The results also reveal that this applies generally across science, social science and arts disciplines.

There are various interesting patterns and practices in supervision applied by the supervisor in the meetings with students and that these vary according to the individual and disciplines. Informants explained how their supervisor supervises them and what goes on during the meetings with him. The results reveal that, in a meeting with a supervisor, there are at least seven important stages that need to be followed in order to establish a good relationship and benefit the student. First students should make an appointment with their supervisor. Second, they should have a record book, diary or tape recorder to record the contents of the meeting. The supervisor or student should start the meeting by asking social questions. Then they should discuss the main agenda, with students doing a lot of talking at this stage. The supervisor should provide feedback on the student's work. Then the meeting should be drawn to a conclusion when most problems have been solved. Also, an appointment for the next meeting should be fixed.

One of the contributions relates to the improvement of practice in the supervision of students. The literature shows that, in supervising students, a supervisor needs to adopt different modes of supervision depending on individual requirements, which are influenced by the attributes of the students ${ }^{[4,15,44,50,59]}$. Supervisors tend to generalise the supervision given to each student under their supervision. Also, if guidelines exist, the supervisor may choose to follow them, choosing the most suitable one. The information in the guidelines should then ensure that the supervision is well arranged and managed. In fact, a model for supervisor and overseas student meetings is useful as a guideline for such meetings. Figure 1 illustrates the model.

Each stage of this model has it's own advantages. So, if students follow these stages, they may get benefits in their personal and professional development. Stage one is very useful if the student found that his/her supervisor is not very easy to meet. By fixing the appointment, students don't have to waste their time waiting for their supervisor to become available. If necessary, students can also list their concerns about their research before the meeting so that they can express their opinion or ask their supervisor a question during the meeting. Stage two is also useful to each student for the purpose of recording the meeting agenda so that it can be reviewed when necessary. For overseas Ph.D students whose English language is not very good, tape-recording the meeting can be meaningful as students can review it to determine exactly what the content of a meeting was. Stage three is useful in order to maintain a good relationship between a student and a supervisor. If the student and supervisor can also talk about social or personal matters for a few minutes in the meeting, the meeting will be more meaningful as the supervisor will be seen as taking care of the student, who, in turn will feel that there is someone who cares about him/her.

Stage four begins with the student talking about his/her work. The findings from this study suggest that talking things over with someone can often solve students' problems and develop their thinking. Besides, students can become more familiar with their research as well as improving their English language skills if they can do more talking to explain their work to their supervisor. Some students submit their written work a few days before the meeting and some bring the written 
work at that time. So, in stage five, supervisor should comment on the student's work and they should discuss the work together. By stage six, most of the student's problems or enquires should be answered. If students make a list of their concerns or problems before attending the meeting, by this stage they have to make sure that all the questions on the list have been answered. Some supervisors suggest that a student has a

Students should make an appointment to meet their supervisor. This can be done by e-mail, telephone or through the supervisor's secretary, or the appointment may have been fixed during the previous meeting.

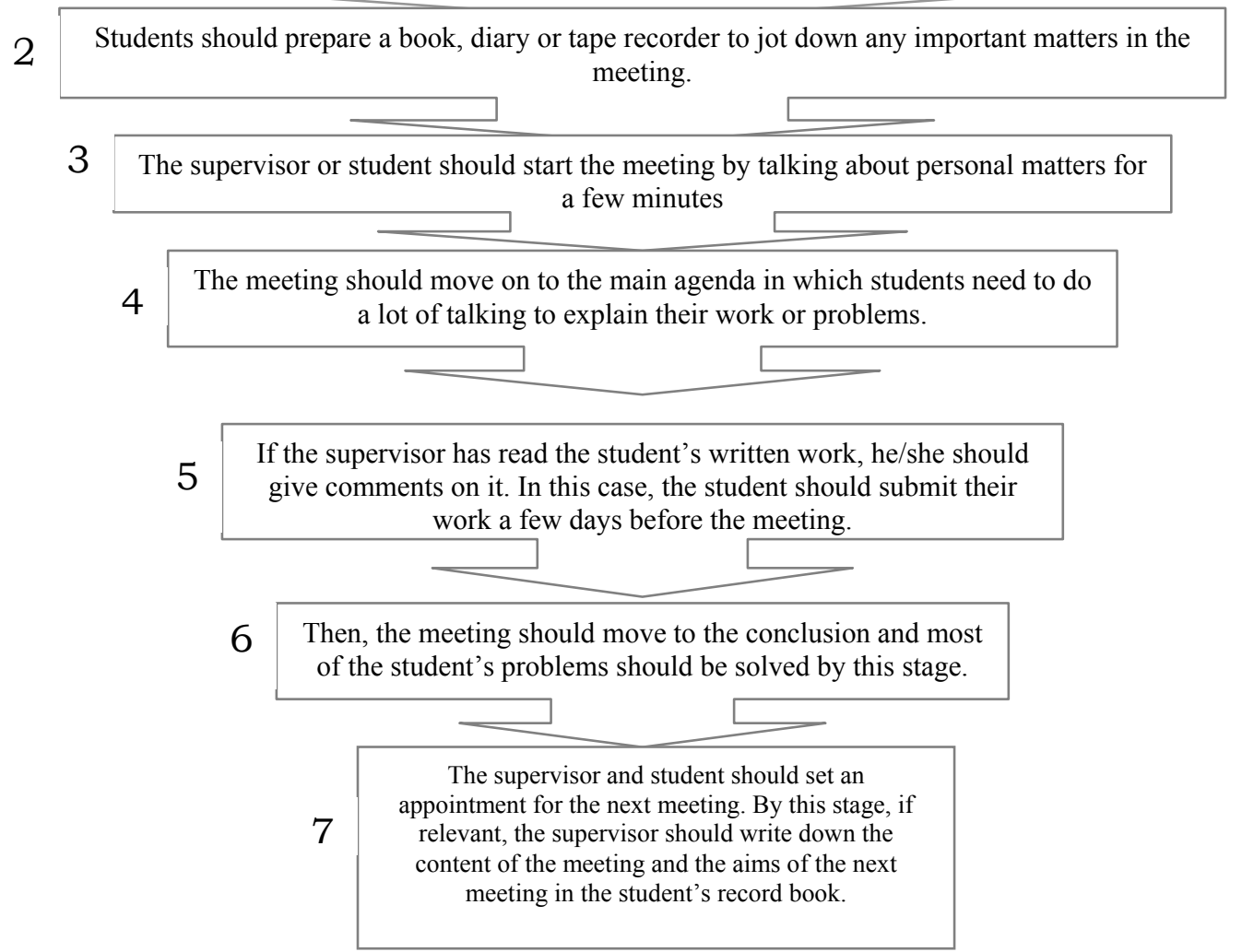

Fig. 1: Model for a supervisor and Ph.D student meeting

research planner/log and some students take the decision to use it because they find that it is useful and suits them. As mentioned, the purpose of this $\log$ is to know what the meeting is all about and what is next. Both student and supervisor should sign the student log. In the last stage, if necessary, the supervisor and student can fix the next meeting. The advantage of this stage is that students know their working deadlines so that they can work towards them. They are responsible for their Ph.D studies, so it can be seen that their work is more organised and well-managed if they are setting certain deadlines.

Secondly, the study has revealed that, in science disciplines, it is best to have two meetings with the supervisor, known as laboratory and personal meetings. Having both personal and laboratory-based meetings is very helpful for science-based students. This is because most science students do quite similar research under the same supervisor and therefore depend on each other. If the laboratory meeting does not meet a student's needs, then he/she can consult his/her supervisor in a personal meeting. Another new finding is that students who have two supervisors tend to go to their second supervisor more frequently when they need assistance. A further one is that e-mail plays an important role in speeding up communication. It at least enables students to resolve some of their problems without them having to wait and fix an appointment.

\section{CONCLUSION}

This research has explored the experience, practices and problems of overseas $\mathrm{Ph}$. D students in the United Kingdom with particular reference to those from 
Malaysia. In doing a Ph.D, overseas students face problems with their research, their supervision, the English language and their families and cultural problems. It is not easy to overcome all these problems without enthusiasm, strength, support and commitment. It has, in particular, been found that overseas Ph.D students need more support and motivation from their supervisor, department or school and the other people surrounding them, like their families and friends. They need someone to talk to, to refer to and to tell them whether they are doing good work or not. Furthermore, the person who is closest to them in a professional relationship is their supervisor. As the UK education system is not examination oriented, in doing a Ph.D, the student relies on a supervisor. Students should have a good relationship with their supervisor, because this will lead to them getting many benefits in their study. This research has also revealed the best practices in a meeting with a supervisor. The findings in this research can improve practices and it is hoped that many people can benefit from them and that they will lead to better support for students.

It is no doubt that meeting could resolve many questions and problems. The same thing goes to graduate research students and their supervisors. The supervisor's guiding and advising role could assist the students to complete their Ph.D programme as planned. However, this could only be happened depending on the students' attitude and the effectiveness of them using the opportunity. Therefore, any students that able to maximise the opportunity during the meeting with the supervisor will be getting the full benefit and make progress efficiently. Students must take seriously of the preparation before attending the meeting, during the meeting and action taken after the meeting. This study had developed an effective student and supervisor meeting model. Even though the model was simple but it could make a great positive impact if it was fully utilized.

\section{REFERENCES}

1. Ballard, B. and J. Clanchy, 1993. Supervising Students from Oversees. In Holdaway, E., Deblois, C. and I. Winchester, 1995. Supervision of Graduate Students. The Canadian J. Higher Education, XXV: 1-29.

2. Council of Graduate Schools, 1990. Research Student and Supervisor. In Donald, J.G., Saroyan, A. and B. Denison, 1995. Graduate Student Supervision Policies and Procedures: A Case Study of Issues and Factors Affecting Graduate Study. The Canadian J. Higher Education, XXV: 71-92.
3. Binns, T. and Potter, R., 1989. Improving the Effectiveness of Postgraduate Supervision: Never Mind the Quality, Feel the Width. J. Geography in Higher Education, 13: 210-216.

4. Hockey, J., 1996. Strategies and Tactics in the Supervision of UK Social Science Ph.D Students. Qualitative Studies in Education, 9: 481-500.

5. Smith, R., 1989. Research Degrees and Supervision in Polytechnics. J. Further and Higher Education, 13: 76-83.

6. Frischer, J. and Larsson, K., 2000. Laissez-faire in Research Education - An Inquiry into A Swedish Doctoral Program. Higher Education Policy, 13: 132-155.

7. Buckley, P.J. and Hooley, G.J., 1988. The NonCompletion of Doctoral Research in Management: Symptoms, Causes and Cures. In Haksever, A. M. and E. Manisali, 2000. Assessing Supervision Requirements of Ph.D Students: The Case of Construction Management and Engineering in the UK. European J. Engineering Education, 25: 1932.

8. Phillips, E.M. and Pugh, D.S., 2000. How to Get a Ph.D- A Handbook for Students and Their Supervisors. Buckingham: Open University Press.

9. Moses, I., 1992. Good Supervisory Practice. In Holdaway, E., Deblois, C. and I. Winchester, 1995. Supervision of Graduate Students. The Canadian J. Higher Education, XXV: 1-29.

10. Powles, M., 1989. How's your Thesis Going? In Holdaway, E., Deblois, C. and I. Winchester, 1995. Supervision of Graduate Students. The Canadian J. Higher Education, XXV: 1-29.

11. Powles, M., 1993. Staff Development for Ph.D Supervision. In Philips, E.M. and Pugh, D.S., 2000. How to Get a Ph.D. Milton Keynes: Open University Press.

12. Moses, I., 1985. Supervising Postgraduates. In Holdaway, E., Deblois, C. and I. Winchester, 1995. Supervision of Graduate Students. The Canadian J. Higher Education, XXV: 1-29.

13. Haksever, A.M. and Manisali, E., 2000. Assessing Supervision Requirements of Ph.D Students: The Case of Construction Management and Engineering in the UK. European J. Engineering Education, 25: 19-32.

14. Hockey, J., 1997. A Complex Craft: United Kingdom Ph.D Supervision in the Social Sciences. Research in Post-Compulsory Education, 2: 45-68.

15. McQueeney, E., 1996. The Nature of Effective Research Supervision. J. Further and Higher Education in Scotland, 20: 23-31. 
16. Sayed, Y., Kruss, G. and Badat, S., 1998. Students' Experience of Postgraduate Supervision at the University of the Western Cape. J. Further and Higher Education, 22: 275-285.

17. Science and Engineering Research Council (SERC), 1983. Research Student and Supervisor: An Approach to Good Supervisory Practice. London: SERC.

18. Yeatman, A., 1995. Making Supervision Relationships Accountable: Graduate Student Logs. Australian Universities’ Review, 38: 9-11.

19. Cullen, D.J., Pearson, M. Saha, L. and Spear, R.H., 1994. Establishing Effective Ph.D Supervision. Commonwealth of Australia: Australian Government Publishing Service.

20. Grant, B. and A. Graham, 1994. Guidelines for Discussion: A Tool for Managing Postgraduate Supervision. In McQueeney, E., 1996. The Nature of Effective Research Supervision. J. Further and Higher Education in Scotland, 20: 23-30.

21. Kam, B.H., 1997. Style and Quality in Research Supervision: The Supervisor Dependency Factor. Higher Education, 34: 81-103.

22. Moses, I., 1994. Supervision of Higher Degree Students- Problem Areas and Possible Solutions. Higher Education Research and Development, 3, 153-165.

23. Parry, S. and Hayden, M., 1994. Supervising Higher Degree Research Students. An Investigation of Practices Across a Range of Academic Departments. Commonwealth of Australia: Australian Government Publishing Service.

24. Bargar, R.R. and J. Mayo-Chamberlain, 1983. Advisor and Advisee Issues in Doctoral Education. J. Higher Education, 54: 407-432.

25. Piccinin, S.J., 2000. Graduate Student Supervision: Resources for Supervisors and Students. Triannual Newsletter, Centre for Development of Teaching and Learning (CDTL). CDTLink: University of Ottawa, Canada.

26. Salmon, P., 1992. Achieving a Ph.D- Ten Students' Experience. Staffordshire: Trentham Books Limited.

27. Bowen, W.G. and Rudenstine, N.L., 1992. In Pursuit of the Ph.D. Princeton, NJ: Princeton University Press.

28. Rudd, E., 1985. A New Look at Postgraduate Failure. In Acker, S., Hill, T. and E. Black, 1994. Thesis Supervision in the Social Science: Managed or Negotiated? Higher Education, 28: 483-498.

29. Hockey, J., 1995. Getting Too Close: A Problem and Possible Solution in Social Science Ph.D
Supervision. The British J. Guidance and Counselling, 23: 199-210.

30. Bond, S., 1991. Agencies Supportive to Nursing Research. In McQueeney, E., 1996. The Nature of Effective Research Supervision. J. Further and Higher Education in Scotland, 20: 23-30.

31. Clarke, R.D., 2000. Give Good Guidance. Black Enterprise, 31: 75-77.

32. Sheehan, J., 1993. Issues in the Supervision of Postgraduate Research Students in Nursing. J. Advanced Nursing, 18: 880-885.

33. Winfield, G., 1987. The Social Science Ph.D, The ESRC Inquiry on Submission Rates: The Report. London: Economic and Social Research Council.

34. Claxton, G., 1989. Being a Teacher. In Smith, P. and West-Burnham, J., 1993. Mentoring in the Effective School. Essex: Redwood Books.

35. Schon, D.A., 1987. Educating the Reflective Practitioner. San Francisco: Jossey-Bass.

36. Shaw, R., 1992. Can Mentoring Raise Achievement in Schools? In Brooks, V. and Sikes, P., 1997. The Good Mentor Guide- Initial Teacher Education in Secondary Schools. Buckingham: Open University Press.

37. Wilkin, M., 1992. Mentoring in Schools. London: Kogan Page.

38. Acker, S., Hill, T. and E. Black, 1994. Thesis Supervision in the Social Science: Managed or Negotiated? Higher Education, 28: 483-498.

39. Cryer, P., 2000. The Research Student's Guide to Success. Buckingham: Open University Press.

40. Graves, N. and Varma, V., 1999. Working for a Doctorate- A Guide for the Humanities and Social Sciences. London: Routledge.

41. Stones, E., 1984. Supervision in Teacher Education. London: Methuen \& Co. Ltd.

42. Delamont, S. and Eggleston, J., 1983. A Necessary Isolation? In Hockey, J., 1996. Strategies and Tactics in the Supervision of UK Social Science Ph.D Students, Qualitative Studies in Education, 9: 481-500.

43. Krebs, H.A., 1967. The Making of a Scientist. Nature, 215: 1441-1445.

44. Welch, 1980. The Postgraduate Student: Progress and Problems Unpublished Ph.D Department of Education, University of Aberdeen. In McQueeney, E., 1996. The Nature of Effective Research Supervision. J. Further and Higher Education in Scotland, 20: 23-30.

45. Marsh, A., 1972. Postgraduate Students' Assessment of Their Social Science Training (SSRC Survey Unit Occasional Paper No. 2). London: Social Science Research Council. 
46. Welsh, J. M., 1979. The First Year of Postgraduate Research Study. Guildford: Society for Research into Higher Education (SRHE).

47. Wright, J. and R. Lodwick, 1989. The Process of the Ph.D: A Study of the First Year of Doctoral Study. Research Papers in Education, 4: 22-56.

48. Russell, A., 1996. Postgraduate Research: Student and Supervisor Views. The Flinders University of South Australia.

49. Brown, G. and Atkins, M., 1988. Effective Teaching in Higher Education. London: Methuen.

50. Brown, R.D. and L. Krager, 1985. Ethical Issues in Graduate Education: Faculty and Student Responsibilities. J. Higher Education, 56: 403-418.

51. Goodyear, R., Crego, C. and M. Johnston, 1992. Ethical Issues in the Supervision of Student Research: A Study of Critical Incidents. Professional Psychology: Research and Practice, 23: 203-210.

52. Connell, R., 1985. How to Supervise a Ph.D. Vestes, 2: 38-41.

53. Waitie, D., 1994. Understanding Supervision: An Exploration of Aspiring Supervisors' Definitions. J. Curriculum and Supervision, 10: 60-76.

54. Sheehan, P., 1994. From Thesis Writing to Research Application: Learning the Research Culture. In McQueeney, E. 1996. The Nature of Effective Research Supervision. J. Further and Higher Education in Scotland, 20: 23-30.
55. Burgess, R.G., Pole, C.J. and J. Hockey, 1994. Strategies for Managing and Supervising the Social Science Ph.D. In Hockey, J. (1996). Strategies and Tactics in the Supervision of UK Social Science $\mathrm{Ph} . \mathrm{D}$ Students, Qualitative Studies in Education, 9: 481-500.

56. Spear, R.H., 2000. Supervision of Research Students: Responding to Student Expectations. The Australian National University, Canberra.

57. Armitage, S. and C. Rees, 1988. Project Supervision. Nurse Education Today, 8: 99-104.

58. Donald, J.G., Saroyan, A. and B. Denison, 1995. Graduate Student Supervision Policies and Procedures: A Case Study of Issues and Factors Affecting Graduate Study. The Canadian J. Higher Education, XXV, 71-92.

59. Hill, T., Acker, S. and E. Black, 1994. Research Students and their Supervisor. In McQueeney, E. (1996). The Nature of Effective Research Supervision. J. Further and Higher Education in Scotland, 20: 23-30. 